\title{
Organometallic chemistry of diphosphazane ligands
}

\author{
S S KRISHNAMURTHY \\ Department of Inorganic and Physical Chemistry, Indian Institute of Science, Bangalore \\ 560012 , India
}

\begin{abstract}
The reactions of a range of acyclic, cyclic and bicyclic diphosphazanes with several transition metal organometallic derivatives have been investigated. The structures of the products have been deduced from IR and NMR spectroscopic data and confirmed by single crystal X-ray analysis of a few representative compounds.
\end{abstract}

Keywords. Diphosphazane ligands; group 6, iron carbonyl and $\mathrm{Pd}, \mathrm{Pt}$ and $\mathrm{Rh}$ complexes.

\section{Introduction}

The ubiquitous use of tertiary monophosphines and diphosphines as ligands in transition metal organometallic chemistry is well documented (Pignolet 1983; Puddephatt 1982; Wilkinson 1982). In recent years, interest in the organometallic chemistry of a class of ligands known as diphosphazanes or diphosphinoamines(I) has been growing rapidly (King 1980; Blagg et al 1985; Ellermann et al 1985; de Leeuw et al 1989; Hill et al 1989; Mague et al 1989; Uson et al 1989) since a range of such ligands with different substituents on nitrogen and phosphorus can be readily synthesised from suitable chloro precursors (Keat et al 1981; Hill et al 1989). Cyclophosphazanes(II) are also readily accessible from the same type of reactions viz. condensation of chlorophosphanes with primary amines or their silylated derivatives) that lead to the acylic diphosphazanes(I) (Keat 1982, 1987). The coordination chemistry of cyclodiphosphazanes(II) has been investigated only to a limited extent as compared to that of the acyclic diphosphazanes(I) (Burckett St. Laurent et al 1983; Scherer et al 1984). Bicyclic diphosphazanes(III, $\mathrm{R}=\mathrm{Bu}^{\prime}$ ) were first reported by Keat and Thompson (1977). Recently our group has reported the synthesis of several new bicyclic diphosphazanes(III, $\mathrm{R}=\mathrm{Ph}$ ) and crystallographic studies on two such compounds have revealed a puckering of the $\mathbf{P}-\mathbf{N}$ ring in a manner opposite to that observed for cis-(RNPX) $)_{2}$ type compounds(II) (Kumaravel et al 1988). It would be interesting to investigate the effect of this novel structural feature on the ligating<smiles>[Y20]N[R12]</smiles>

1<smiles></smiles>

II<smiles>[R]P1NP2CCCCCC12[Y]</smiles>

III 
behaviour of III and compare the results with those available for other phosphorus cage compounds (Stricklen et al 1983). For the last 4-5 years, we have been interested in the organometallic chemistry of diphosphazanes(I-III) (Balakrishna 1989; Balakrishna et al 1989, 1990) and a brief review of recent results is presented in this paper.

\section{Reactions of diphosphazanes with group 6 metal- and iron carbonyl derivatives}

We have earlier reported that the reactions of several diphosphazane ligands $(I, R=$ $\mathrm{Me}$ or $\mathrm{Ph}, \mathrm{X}=\mathrm{OCH}_{2} \mathrm{CF}_{3}$ or $\mathrm{OPh} ; \mathrm{R}=\mathrm{Pr}^{i}, \mathrm{X}=\mathrm{Ph}$ ) with metal carbonyl derivatives generally yield monometallic chelate complexes, $\left[\mathrm{M}(\mathrm{CO})_{n}\left(\mathrm{~L}_{2}-\mathrm{PP}^{\prime}\right)\right]\left(\mathrm{L}_{2}=\right.$ diphosphazane, $\mathrm{M}=\mathrm{Cr}, \mathrm{Mo}$ or $\mathrm{W}, n=4 ; \mathrm{M}=\mathrm{Fe}, n=3$ ) (Balakrishna 1989; Balakrishna etal 1990). The structures of two such compounds, $\left[\mathrm{M}(\mathrm{CO})_{4}\left\{\left(\mathrm{Ph}_{2} \mathrm{P}\right)_{2} \mathrm{NPr}^{i}\right\}\right]$ and $\left[\mathrm{M}(\mathrm{CO})_{4}\left\{(\mathrm{PhO})_{2} \mathrm{PN}(\mathrm{Ph}) \mathrm{P}(\mathrm{OPh})_{2}\right\}\right]$ have been confirmed by single crystal $X$-ray analysis (Balakrishna et al 1989a). The mean $\mathrm{P}-\mathrm{N}$ distance $(1.71 \AA)$ in the former complex shows little variation from that of the free ligand (Keat et al 1981); however, the $\mathrm{P}-\mathrm{N}-\mathrm{P}$ angle $\left[122.8(3)^{\circ}\right]$ in the ligand (which exists in $C_{s}$ conformation in the solid state) decreases to $102.9(5)^{\circ}$ upon chelate formation.

The reaction of $\left[\left\{\mathrm{Fe}\left(\eta^{5}-\mathrm{C}_{5} \mathrm{H}_{5}\right)(\mathrm{CO})_{2}\right\}_{2}\right]$ with the diphosphazaneI $(\mathrm{R}=\mathrm{Ph}, \mathrm{X}=$ $\mathrm{OPh}$ ) in boiling benzene affords two isomeric complexes IV and V (scheme 1) whose structures have been established from elemental analyses, IR spectra and ${ }^{31} \mathrm{P}$ NMR measurements. The formation of $\mathrm{V}$ is interesting in that it involves the cleavage of one of the $\mathrm{P}-\mathrm{N}$ bonds of the ligand to give the fragments $(\mathrm{PhO})_{2} \mathrm{P}=\mathrm{NPh}$ and $\mathrm{P}(\mathrm{OPh})_{2}$ both of which act as bridging ligands between the two iron centres. Such a cleavage of the $P-N$ bond in diphosphazanes has been observed by Brown et al (1976) in the reaction of $\mathrm{MeN}\left(\mathrm{PF}_{2}\right)_{2}$ with $\left[\left\{\mathrm{Fe}\left(\eta^{5}-\mathrm{C}_{5} \mathrm{H}_{5}\right)(\mathrm{CO})_{2}\right\}_{2}\right]$.

Seven-coordinated Mo(II) and W(II) complexes of diphosphazanes(I) have been synthesized as shown in scheme 2 . The structure of the tungsten complex VI $(R=P h$, $\mathrm{X}=\mathrm{OPh}$ ) (determined by single crystal $\mathrm{X}$-ray analysis) reveals a pentagonal bipyramidal geometry around the metal. One $\mathrm{CO}$ group, the two iodine and the two phosphorus atoms lie in the basal plane while the other two $\mathrm{CO}$ groups occupy the
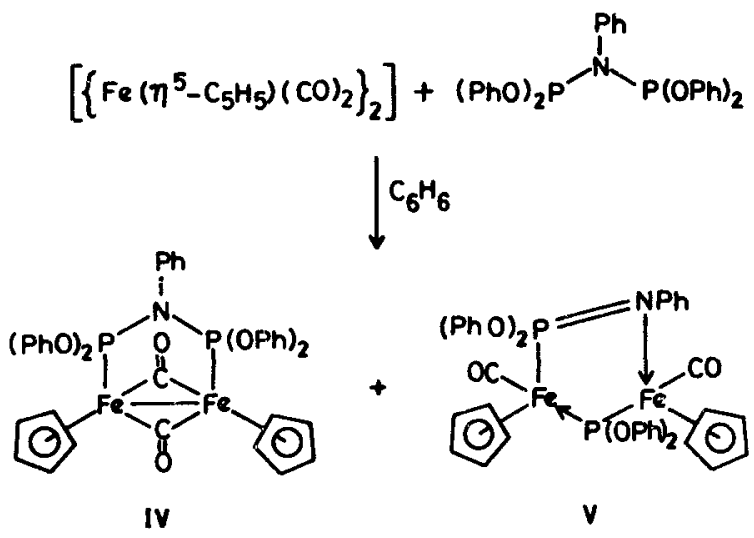

Scheme 1. 


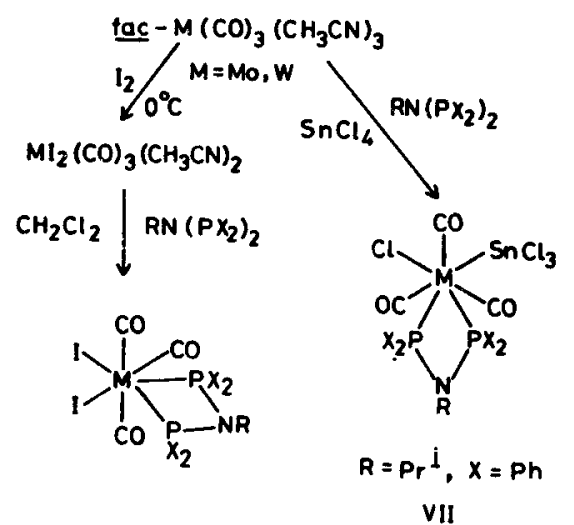

$$
\begin{aligned}
& R=M e, P h, x=0 P h \\
& R=P r i, x=P h \\
& V_{i}
\end{aligned}
$$

Scheme 2.

apical positions. Seven-coordinated $\mathrm{Mo}(\mathrm{II})$ or $\mathrm{W}(\mathrm{II})$ complexes of the type $\left[\mathrm{MX}_{2}(\mathrm{CO})_{3}(\mathrm{~L}-\mathrm{L})\right](\mathrm{L}-\mathrm{L}=$ diphosphine or two monophosphines) usually possess a capped octahedral geometry around the metal centre (Drew 1977; Kepert 1979). Pentagonal bipyramidal geometry is found in only one instance, viz. $\left[\mathrm{WI}_{2}(\mathrm{CO})_{3}\left(\mathrm{Ph}_{2} \mathrm{PCH}_{2} \mathrm{PPh}_{2}\right)\right]$ (Foy et al 1980), the exceptional behaviour of which as well as that of $\operatorname{VI}(M=W, R=P h, X=O P h)$ is due to the small 'bite' of the bidentate phosphine or the phosphazane ligand. Recently there has been an upsurge of interest in 7-coordinated Mo(II) and W(II) complexes containing carbonyl groups and nitrogen or phosphorus donor ligands (Baker and Quinlan 1989).

\section{Reactions of I with $\mathrm{Rh}, \mathrm{Pd}$ and Pt derivatives}

The reactions of diphosphazanes $\mathrm{I}(\mathrm{R}=\mathrm{Me}$ or $\mathrm{Ph}, \mathrm{X}=\mathrm{OPh})$ with $[\mathrm{RhCl}(\mathrm{COD})]_{2}$ $\left(\mathrm{COD}=1,5\right.$-cyclooctadiene) and $\left[\mathrm{RhCl}(\mathrm{CO})_{2}\right]_{2}$ lead to the isolation of dinuclear complexes which are shown in scheme 3 . The ${ }^{31} \mathrm{P}$ NMR spectra of these complexes clearly show ${ }^{103} \mathrm{Rh}-{ }^{31} \mathrm{P}$ coupling; the ${ }^{1} J_{\mathrm{RhP}}$ value for the chelate complexes (VIII and IX) is $280 \mathrm{~Hz}$ whereas it is $214 \mathrm{~Hz}$ for complex X which contains bridging diphosphazane ligands. It has been noted by Haines et al $(1979,1981)$ that subtle changes in the nature of the substituents on the phosphorus atoms of diphosphazane ligands can lead to the formation of one or the other type of complexes X and XI.

Several palladium and platinum complexes of diphosphazanes(I) have been prepared as shown in scheme 4. The structure of complex XII reveals an unusually short Pd-Pd distance of $2 \cdot 856$ (3) $\AA$ which may be compared with the values of 2.959(2) $\AA$ and 3.023(1) $\AA$ for the analogous bis(diphenylphosphino)methane complexes of palladium and platinum $\left[\mathrm{M}_{2}(\mathrm{dppm})_{3}\right](\mathrm{M}=\mathrm{Pd}$ or $\mathrm{Pt})$ respectively (Muir et al 1986; Kirss and Eisenberg 1989). The structure of the Pd derivative $\operatorname{XIII}\left(\mathbf{M}=\mathbf{M}^{\prime}=\mathbf{P d}, \mathbf{R}=\mathbf{P h}, \mathbf{X}=\mathbf{O P h}\right)$ has also been determined; the molecule is centrosymmetric and the $\mathrm{Cl}-\mathrm{Pd}-\mathrm{Pd}-\mathrm{Cl}$ linear chain lies on the two-fold axis. The $\mathrm{Pd}-\mathrm{Pd}$ distance of $2 \cdot 619(1) \AA$ is slightly shorter than that $[2 \cdot 638(6) \AA]$ in the recently 


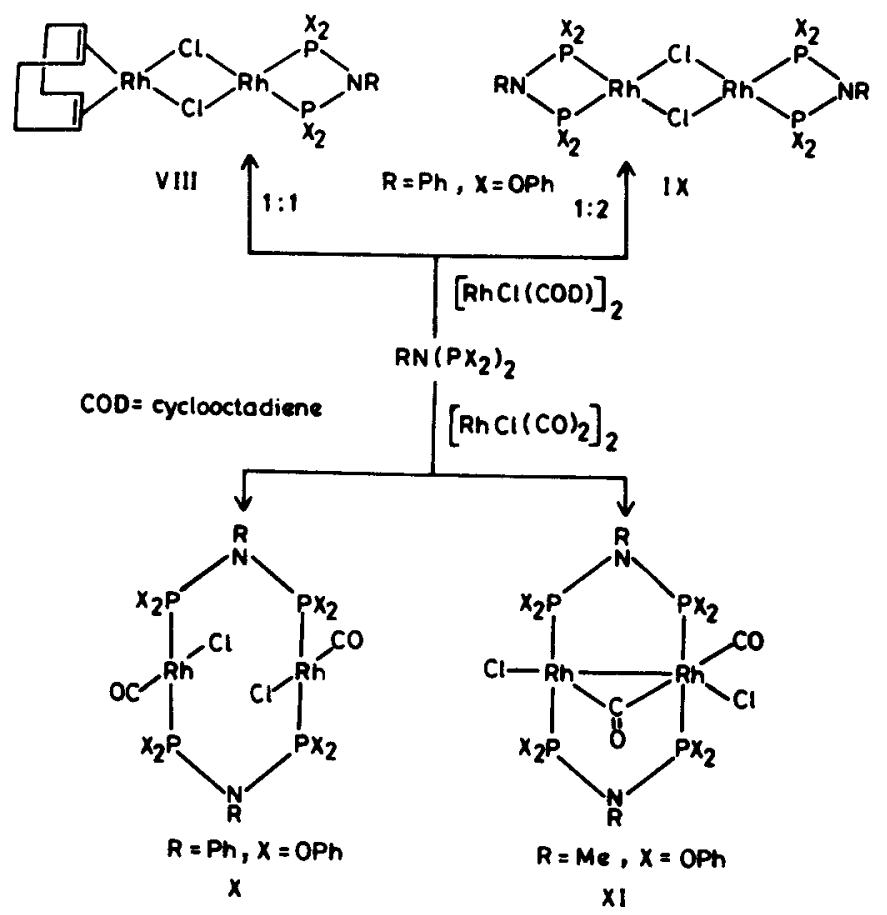

Scheme 3.

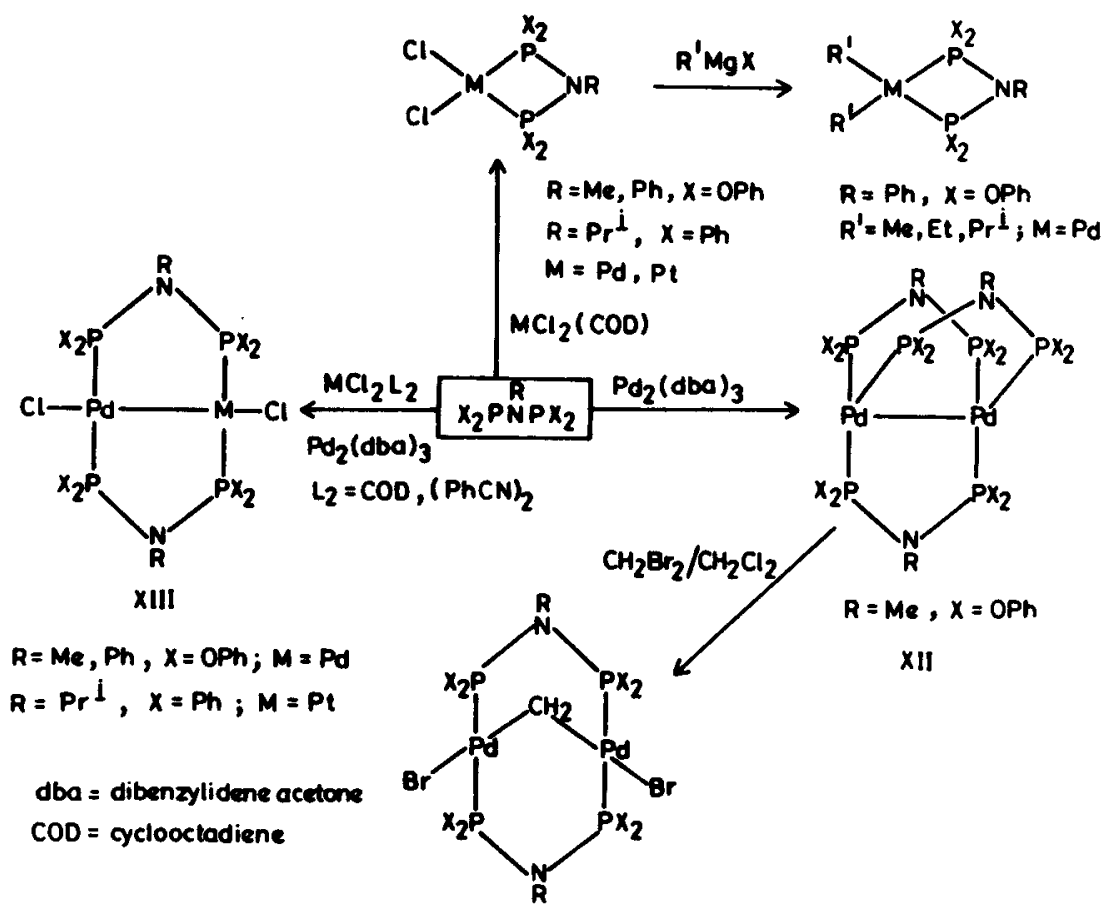

Scheme 4. 
reported bis(diphenylphosphino)amine (dppa) complex, $\left[\mathrm{Pd}_{2} \mathrm{Cl}_{2}(\mathrm{dppa})_{2}\right]$ (Uson et al 1989).

\section{Organometallics of cyclic(II) and bicyclic(III)diphosphazanes}

The reactions of cyclodiphosphazanes (cis II, $\mathrm{R}=\mathrm{Bu}^{\mathrm{t}}, \mathrm{X}=\mathrm{OPh} ; \mathrm{R}=\mathrm{Ph}, \mathrm{X}=$ $\mathrm{OC}_{6} \mathrm{H}_{4} \mathrm{Me}-p$ ) with group 6 hexacarbonyls or their derivatives yield the tetracarbonyl complexes XIV in which the cyclodiphosphazane behaves as a monodentate ligand. Such monoligated mononuclear complexes (XV) are also obtained from the reactions of II with $\left[\mathrm{M}(\mathrm{COD}) \mathrm{Cl}_{2}\right](\mathrm{M}=\mathrm{Pt}$ or $\mathrm{Pd}$ ) (scheme 5). However, the reaction of $\mathrm{II}\left(\mathrm{R}=\mathrm{Ph}, \mathrm{X}=\mathrm{OCH}_{2} \mathrm{CF}_{3}\right.$ ) (which has a trans configuration) with $\left[\mathrm{Mo}(\mathrm{CO})_{4}\left(\mathrm{NHC}_{5} \mathrm{H}_{10}\right)_{2}\right]$ gives the dinuclear complex, $\left.\left[(\mathrm{CO})_{4} \mathrm{Mo}\left(\mathrm{NHC}_{5} \mathrm{H}_{10}\right) \mu \text { - } \mathrm{PhNP}\left(\mathrm{OCH}_{2} \mathrm{CF}_{3}\right)\right]_{2} \mathrm{Mo}(\mathrm{CO})_{4}\left(\mathrm{NHC}_{5} \mathrm{H}_{10}\right)\right]$. (Balakrishna et al 1989a; Sreenivasa Reddy and Krishnamurthy 1989).

Treatment of II $\left(\mathrm{R}=\mathrm{Bu}^{t}, \mathrm{X}=\mathrm{OPh}\right)$ with $[\mathrm{RhCl}(\mathrm{COD})]_{2}$ and $\left[\mathrm{RhCl}(\mathrm{CO})_{2}\right]_{2}$ yield the mononuclear and dinuclear complexes XVI and XVII, respectively (scheme 5). The structure proposed for XVII is tentative; a trimeric (Mague et al 1989) or a tetrameric (Stricklen et al 1983) structure with bridging cyclophosphazane ligands

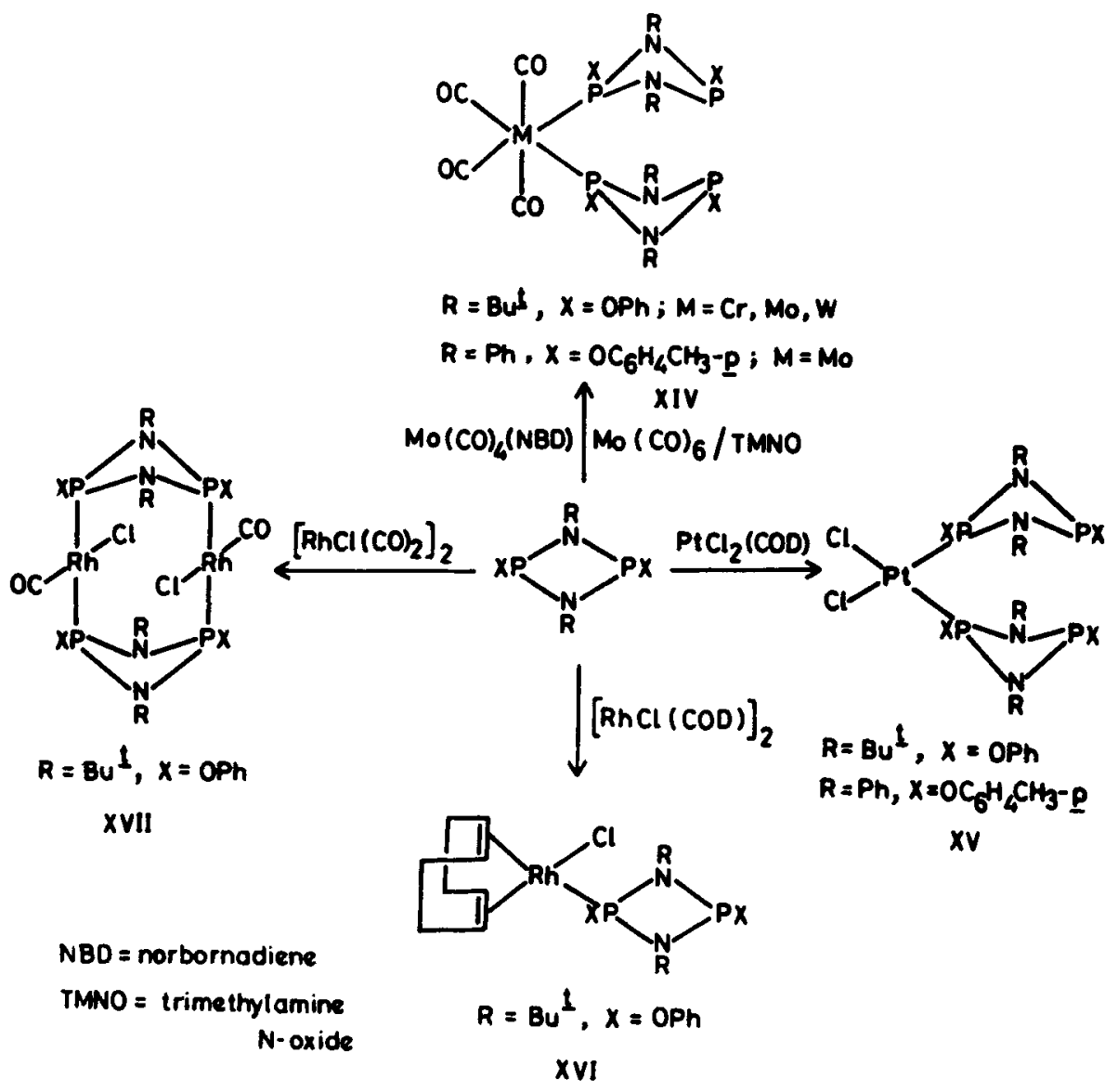

Scheme 5. 
would also be consistent with available analytical and spectroscopic data (Balakrishna 1989).

The bicyclic diphosphazaneIIIa $(\mathrm{R}=\mathrm{Ph}, \mathrm{X}=\mathrm{Y}=0, n=2)$ reacts with fac$\left[\mathrm{M}(\mathrm{CO})_{3}(\mathrm{MeCN})_{3}\right](\mathrm{M}=\mathrm{Mo}$ or $\mathrm{W})$ to afford complexes of the type, fac$\left[\mathrm{M}(\mathrm{CO})_{3} \mathrm{~L}_{3}\right]$ ( $L=$ monoligated diphosphazane) (XVIII). On the other hand, reaction of $\operatorname{IIIa}(\mathrm{X}=\mathrm{Y}=0, n=2)$ with $\left[\mathrm{Mo}(\mathrm{CO})_{4}(\mathrm{pip})_{2}\right]$ or $\left[\mathrm{M}(\mathrm{CO})_{4}(\mathrm{NBD})_{2}\right]$ is not clean and the nature of the products could not be ascertained. However, the reaction of $\operatorname{IIIb}(\mathrm{X}=\mathrm{NMe}, \mathrm{Y}=0, n=2)$ with $\left[\mathrm{Mo}(\mathrm{CO})_{4}(\mathrm{pip})_{2}\right]$ gives a cis-tetracarbonyl complex XIX in which coordination of the diphosphazane through the $\mathrm{P}-\mathrm{O}$ phosphorus is more likely (scheme 6) (Prakasha and Krishnamurthy 1989).

The reactions of IIIa $(R=P h, X=Y=0, n=2)$ with platinum and palladium derivatives have yielded interesting results. Whereas treatment of IIIa with $\left[\mathrm{Pt}(\mathrm{COD}) \mathrm{Cl}_{2}\right]$ gives an insoluble material, the analogous reaction with the palladium derivative gives a complex of composition $\left[\mathrm{Cl}_{2} \mathrm{Pd}(\mu-\mathrm{L})\right]_{n}(\mathrm{~L}=$ diphosphazane $)$. The presence of a bridging diphosphazane is indicated by the ${ }^{31} \mathrm{P}$ chemical shift $(69 \cdot 7 \delta)$ for this complex. The reaction of IIIa with $\left[\left(\mathrm{Et}_{3} \mathrm{P}\right) \mathrm{PdCl}_{2}\right]_{2}$ gives a dinuclear complex $\left[\left(\mathrm{Cl}_{2} \mathrm{PdPEt}_{3}\right)_{2}(\mu-\mathrm{L})\right](\mathrm{L}=$ diphosphazane $)$ in which the two $\mathrm{Et}_{3} \mathrm{P}$ groups have cistrans orientation with respect to the bridging diphosphazane ligand; in contrast, the analogous platinum derivative has a cis-cis disposition of the $\mathrm{PEt}_{3}$ grourps with respect to the bridging diphosphazane ligand (Nixon 1989, private commun.). A notable feature of the NMR spectra of the Pt complexes (XV) of cyclodiphosphazanes(II) and the $\mathrm{Pt}$ complex of the bicyclic diphosphazane(IIIa) referred to above is the

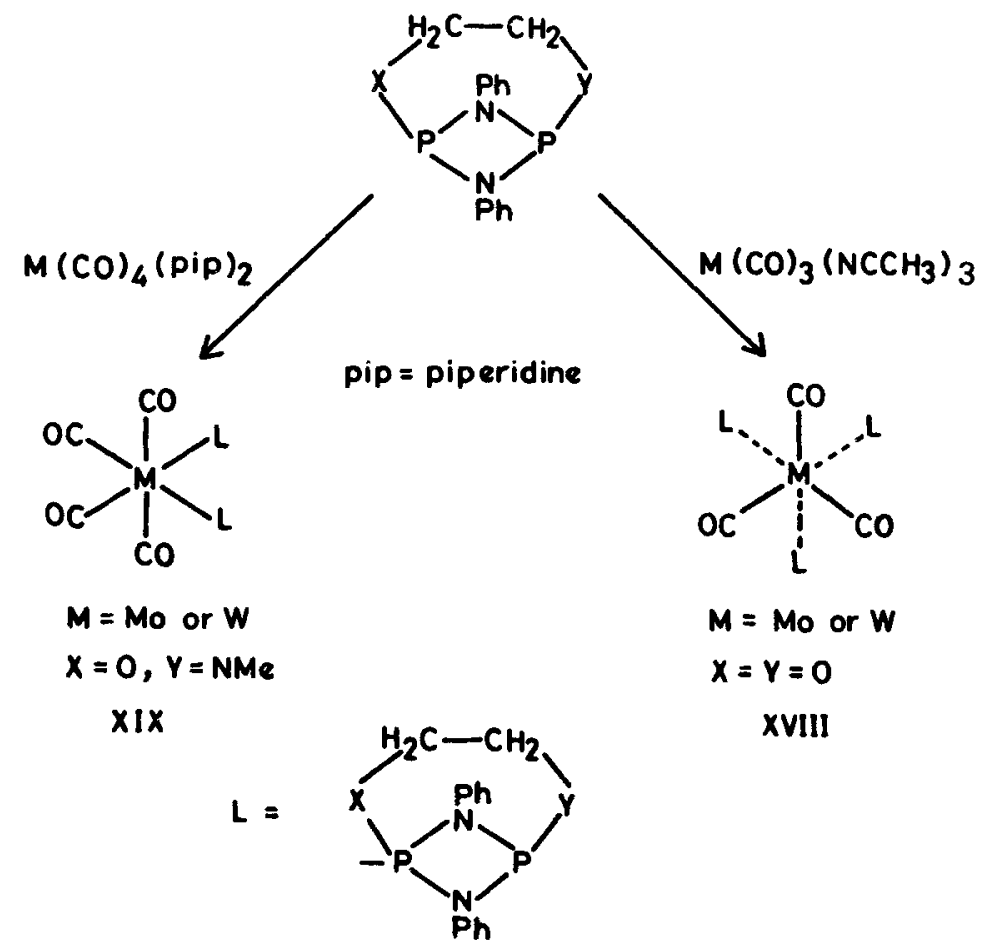

Scheme 6. 
surprisingly large ${ }^{1} J_{\mathrm{PtP}}$ value $(4800-5800 \mathrm{~Hz})$ which is $2000 \mathrm{~Hz}$ higher than that observed for the $\mathrm{PEt}_{3}$ groups bonded to platinum.

\section{Summary and outlook}

The results clearly bring out the versatility and considerable scope of acyclic diphosphazanes(I) as ligands. Pronounced differences in the reactivity pattern and the structures of the resulting products are observed even with minor changes in the nature of the substituents attached to phosphorus and/or nitrogen. Our future studies will be directed towards an understanding of the factors responsible for these differences. Studies with cyclic and bicyclic diphosphazanes also show that they can act as monodentate as well as bridging-bidentate ligands. Some of the complexes isolated may prove valuable synthons for the preparation of bimetallic and highnuclearity clusters and this aspect merits a detailed investigation. The potential utility of some of the complexes as homogeneous catalysts in organic synthesis is another area which will also engage our attention in the future.

\section{Acknowledgement}

It is a pleasure to thank my research students M S Balakrishna, T K Prakasha and V Sreenivasa Reddy for their painstaking and skilful experimental work and Prof. $H$ Manohar, Dr $M$ Nethaji, and $R$ Murugaval (IISc, Bangalore) and Dr V Siriwardane and Prof. N S Hosmane (Southern Methodist University, Dallas, Texas) for collaboration in the X-ray crystallographic work. Financial support from the Department of Science and Technology, New Delhi, is gratefully acknowledged.

\section{References}

Baker P K and Quinlan A J 1989 Inorg. Chim. Acta 162179

Balakrishna M S 1989 Synthetic, spectroscopic and structural studies on transition metal complexes of diphosphazane ligands, $\mathrm{PhD}$ thesis, Indian Institute of Science, Bangalore

Balakrishna M S, Prakasha T K and Krishnamurthy S S 1989a, Proc. Indian Natl. Sci. Acad. A55 335

Balakrishna M S, Prakasha T K, Krishnamurthy S S, Siriwardane U and Hosmane NS 1989b J. Organomet. Chem. (in press)

Balakrishna M S, Prakasha T K and Krishnamurthy S S 1990 Phosphorus, Sulfur and Silicon (in press)

Blagg A, Carr S W, Cooper G R, Dobson I D, Gill J B, Goodall D C, Shaw B L, Taylor N, Boddington T 1985 J. Chem. Soc. Dalton Trans. 1213

Burckett St Laurent J C T R, Hitchcock P B and Nixon J F 1983 J. Organomet. Chem. 249243

Brown G M, Finholt J E, King R B, Bibber J W and Kim J H $1978 \mathrm{~J}$. Am. Chem. Soc. 1001632

de Leeuw G, Field J S and Haines R J 1989 J. Organomet. Chem. 359245

Drew M G B 1977 Prog. Inorg. Chem. 2367

Ellermann J, Szucsanyi G Y and Wilhelm E 1985 Chem. Ber. 1181588

Foy R M, Kepert D L, Raston C L and White A H $1980 \mathrm{~J}$. Chem. Soc., Dalton Trans. 440

Haines R J, Laing M, Meintjies E and Sommerville P 1981 J. Organomet. Chem. 215 C17

Haines R J, Meintjies E and Laing M 1979 Inorg. Chim. Acta 36403

Hill T G, Haltiwanger R C, Prout T R and Norman A D 1989 Inorg. Chem. 283461

Keat R 1982 Top. Curr. Chem. 10289

Keat R 1987 in Chemistry of inorganic homo- and heterocycles (eds) D B Sowerby and I Haiduc (London: Academic Press) vol. 2, p. 407 
Keat R, Muir L M, Muir K W and Rycroft D S $1981 \mathrm{~J}$. Chem. Soc., Dalton Trans 2192

Keat R and Thompson D G 1977 Angew. Chem., Int. Edn. Engl. 16797

Kepert D L 1979 Prog. Inorg. Chem. 2541

King R B 1980 Acc. Chem. Res. 13243

Kirss R U and Eisenberg R 1989 Inorg. Chem. 283372

Kumaravel S S, Krishnamurthy S S, Cameron T S and Linden A 1988 Inorg. Chem. 274546

Mague J T, Johnson M P and Lloyd C L $1989 \mathrm{~J}$. Am. Chem. Soc. 1115012

Muir L M, Muir K W, Grosisel M C, Brown M P, Nelson C D, Yavari A, Kalles E, Moulding R P and Seddon K R 1986 J. Chem. Soc., Dalton Trans. 1955

Pignolet L H (ed.) 1983 Homogeneous catalysis with metal phosphine complexes (New York: Plenum)

Prakasha T K and Krishnamurthy S S 1989 (to be published)

Puddephatt R J 1982 Chem. Soc. Rev. 99

Scherer O J, Anselmann R and Sheldrick W S 1984 J. Organomet. Chem. 263 C26

Sreenivasa Reddy V and Krishnamurthy S S 1989 (to be published)

Stricklen P M, Volcko E J and Verkade J G 1983 J. Am. Chem. Soc. 1052494

Uson R, Fornies J, Navarro R, Thomas M, Fortuno C and Cebollada J I 1989 Polyhedron 81045

Wilkinson G, Stone F G A and Abel E W (eds) 1982 Comprehensive organometallic chemistry (Oxford: Pergamon) 